NISTIR 7180

\title{
Integrated Supply Chain Simulation System (ISSS) - Modeling Requirements and Design Issues
}

Shigeki Umeda

Sanjay Jain 


\section{Integrated Supply Chain Simulation System (ISSS) - Modeling Requirements and Design Issues}

Shigeki Umeda

Sanjay Jain

Manufacturing Systems Integration Division Manufacturing Engineering Laboratory

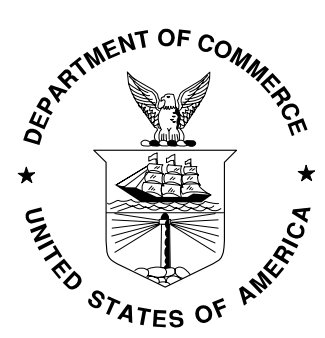

U.S. DEPARTMENT OF COMMERCE

Donald L. Evans, Secretary

TECHNOLOGY ADMINISTRATION

Phillip J. Bond, Under Secretary of Commerce for Technology NATIONAL INSTITUTE OF STANDARDS AND TECHNOLOGY Arden L. Bement, Jr., Director 
Abstract: This paper describes requirements for an integrated supply chain system simulator with the focus on production activities within the system. This paper includes the following contents: (1) Identification of supply chain planning problems over various operational strategies, (2) Operational strategy for supply chain management, and (3) Requirements and design issues for a generic supply chain simulation system.

\section{Introduction}

Modern manufacturing enterprises are required to collaborate with their business partners through their business process operations such as design, manufacture, distribution, and aftersales service. Robust and flexible system mechanisms are required to realize such inter-enterprise collaboration environments.

A supply chain system is a chain of processes from the initial raw materials to the ultimate consumption of the finished product spanning across multiple supplier-customer links. It provides functions within and outside a company that enable the value chain to make products and provide services to the customers.

The supply chain system terminology originated in the "Quick Response" initiative in the '80s. In 1985, Kurt Salmon Associates were commissioned to conduct a supply chain analysis for the apparel industry. The result of this study showed the delivery time for apparel supply chain, from raw material to consumer, was 66 weeks long, 40 weeks of which were spent in warehouses or in transit [1]. This study led to the development of the "Quick Response" (QR) strategy. QR is a partnership in which retailers and suppliers work together to respond more quickly to consumer needs by sharing information.

A group of grocery industry leaders created a joint industry task force called the "Efficient Consumer Response" (ECR) working group in 1992 [1]. This group was charged with examining the grocery supply chain to identify opportunities to make it more competitive. The most remarkable result of this study has been an identification of a set of best practices, which, if implemented, could improve overall performance of the supply chain substantially. The successful adoption of ECR for a manufacturer depends on the manufacturing flexibility, which enables matching supply with demand.

A key to realize this flexibility is nothing other than a process chain that tightly integrates demand management, production scheduling, and inventory deployment to allow the companies to better utilize information, production resources, and inventory [2]. In this sense, practice of manufacturing supply chain management is nothing other than a realization of "Enterprise Integration" applied to material flow and associated information and financial flows across its member companies.

ECR has been succeeded by the concept of "Continuous Replenishment" (CR) [3]. The CR concept is, in a sense, similar to the Japanese Just-In-Time system concept, which is based on a pull system based on consumer demand. Point-of-Sales system was introduced to forward sales transactions directly to manufacturers by computers to keep retailers replenished and balanced just-in-time.

More recently, a Supply Chain Operations Reference (SCOR) model has been defined as a generic process model [4]. The SCOR model can be used to describe supply chains using a common framework and terminology. It defines five process types: PLAN, SOURCE, MAKE, DELIVER, and RETURN, that can be used to describe a supply chain. Levels of detail can be successively added to understand the processes involved. Best practices are being defined at the detailed levels to help industry implement them and measure their own performance.

Modern information and communication technologies have enabled high-speed and low-cost communications. These have accelerated commercial use of the Internet, as is seen in e-marketplaces by increasing use of broadband communications. Such e-marketplaces are currently used not only in consumers' purchase but also for business-to-business (B2B) purchases among worldwide suppliers [5]. Enterprises must integrate all their business processes to compete and participate in the global business community.

The key to realizing such business-process integration depends on well-organized mechanisms for 
sharing information among supply chain member companies. Powerful tools are needed to support design and operation of such information systems. Simulation is one such powerful tool that can be used to support decisions at design and operational phases.

This paper describes modeling requirements and design issues for a generic simulation system that can support design, planning, and operation of supply chain systems. The primary purpose of a supply chain is to provide a manufactured product to the end-customer. This paper focuses on manufacturing activities in supply chains in discrete products industries. Also, the discussion here primarily emphasizes the simulation model functional capabilities without making it specific to a process model. While some of the terminology used is similar to that of the SCOR model, the discussion is applicable to supply chain systems described using other process models that may be specific to ERP (Enterprise Resource Planning) and APS (Advanced Planning and Scheduling) software solution vendors, to an industry or to a group of companies partnering in a supply chain.

This section introduced the topic and defined the scope of this paper. Section 2 describes manufacturing operational strategies, which are deeply related to supply chain configurations. Section 3 discusses supply chain planning problems. These problems will be categorized into several core problems within the production and logistics management area. Section 4 summarizes general characteristics of simulation technologies for performance evaluation, and the advantages it offers for application to supply chain problems. Section 5 discusses requirements for generic supply chain simulators. Four modeling views will be introduced in this section. These are "Organization view," "Activity view," "Control view" and "Information system view." A modeling framework for supply chain system simulation is also presented. Section 6 describes supply chain operation and data from the viewpoint of discrete event simulation. Examples are provided for generic structures of supply chain simulation models. Section 7 provides other requirements for effective use of a generic simulator for performance evaluation of supply chain systems. Section 8 concludes the paper with discussion of future research.

\section{Manufacturing operational strategies}

One of the important decisions while designing manufacturing systems is to define its operational strategy in production and inventory management. Generally, there are four types of operational policies with regards to material management [7]. These are MTS (Make To Stock), MTO (Make To Order), ATO (Assemble To Order), and ETO (Engineering To Order), respectively.

These operational strategies can be also expanded to design the supply chain systems, which are composed of multiple manufacturing firms. One of the primary objectives of a supply chain system is to minimize inventory costs and that can be achieved by individual chain members synchronizing their processes with each other in order to meet customers' demands just in time. An MPS (Master Production Schedule) should be defined at the supply chain level to represent as efficiently as possible what manufacturing will make. Strategies similar to the manufacturing operational strategies discussed in this section can be used to decide the most efficient production management strategy for a supply chain depending on the environment in which it operates.

MTS (Make To Stock) system is a production environment where products can be and usually are finished before receipt of a customer order. The customer has little direct involvement in deciding the product features. In this environment, suppliers manufacture the goods and sell from the finished goods inventory. Customer orders are typically filled from existing stocks, and the MPS is usually a schedule for producing finished-goods items to replenish those stocks. Figure 1 shows a representation of the MTS strategy. The selection of the replenishment point is usually a difficult problem and dependent on the individual case. A major input for this determination is the demand forecast. Classical EOQ model may be applicable only when the demand of finished goods is independent and fairly uniform [5]. STS (Stock To Sales) is a special case of MTS used by retailers for managing finished goods stocks.

The MTS strategy is suitable for manufacturing products with the following characteristics:

- Their demand is roughly constant or easy to forecast.

- Their customer has little direct involvement in deciding the product features. 
The typical examples of such products are electrical and electronic appliances such as televisions and refrigerators.

Figure 1. Make To Stock (MTS) strategy
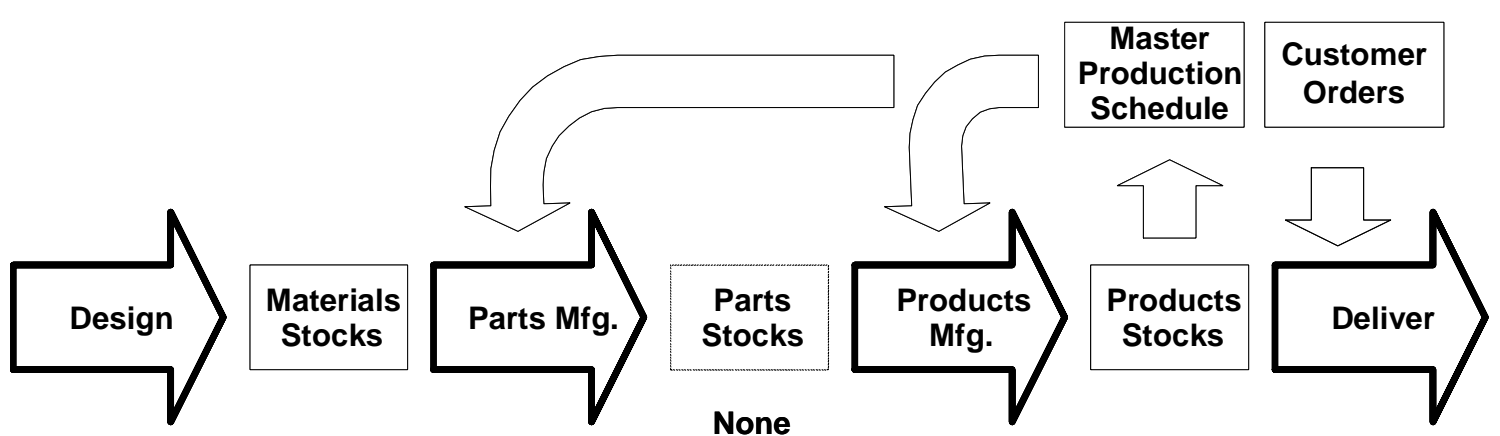

In case of the MTO (Make To Order) strategy, the manufacturing of products is started after the receipt of customer's order. The manufacturers in the chain do not start to make the products until a customer's order is received. Supply chain has, in principle, neither products stock nor parts stock. Delivery lead-time is usually long. Figure 2 represents the operation of MTO strategy. The MTO strategy is suitable for products with the following characteristics:

- The product features depend on customers' requirements.

- The final product is a combination of standard items and items custom-designed to meet the special needs of the customer.

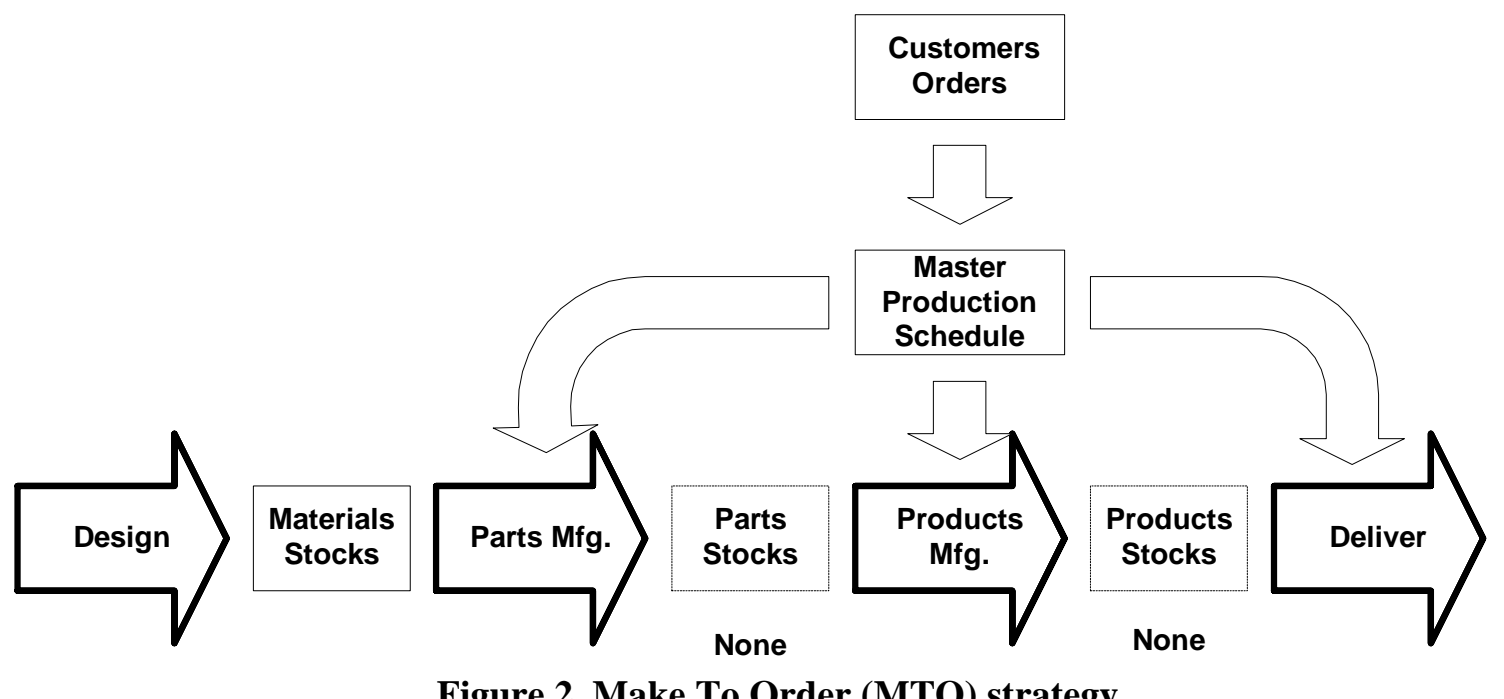

ETO (Engineering-To-Order) strategy is used where the customer's specifications require unique engineering design or significant customization. This is a special form of MTO. In this environment, the product is designed and manufactured after receiving a customer order based on the customer's very special needs. Inventory will not normally be purchased until needed by the manufacturer. Delivery lead-time is long because it includes not only the procurement lead-time but also the design lead-time. Figure 3 represents the ETO strategy operation. 

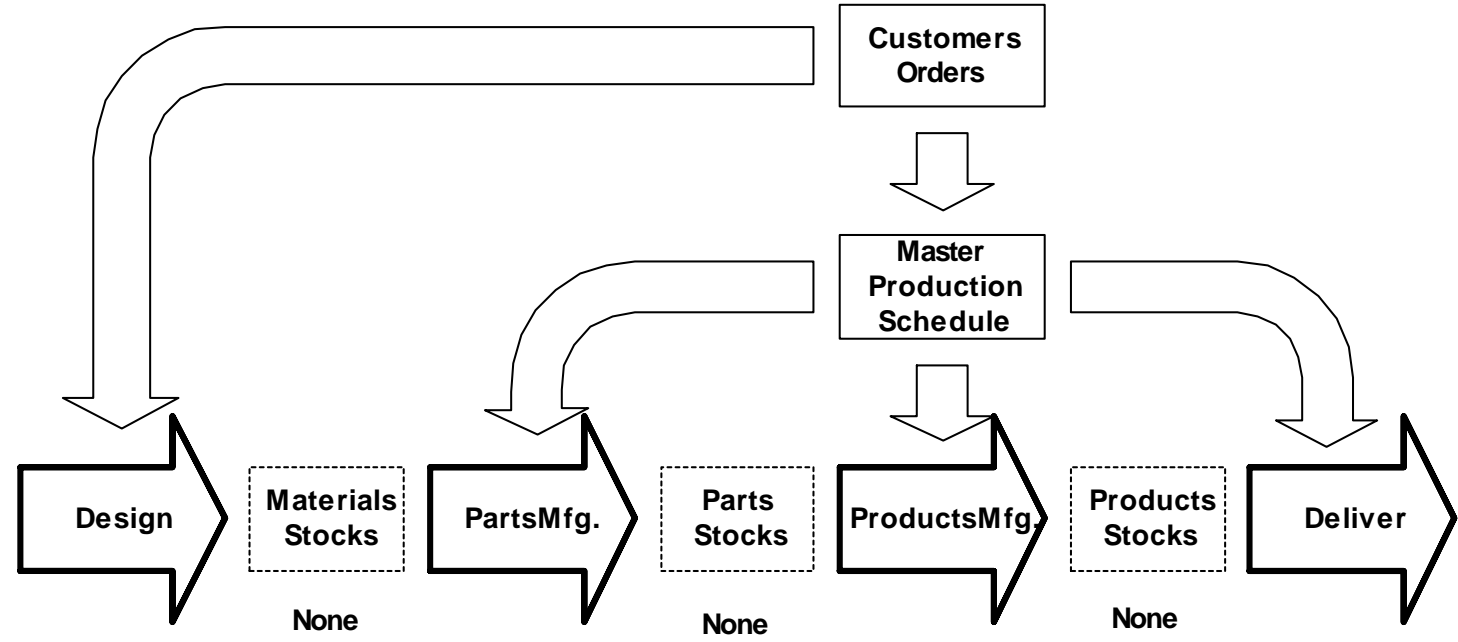

Figure 3. Engineer To Order (ETO) strategy

Where options are accessories that are stocked before customer orders arrive, the term ATO (Assemble To Order) is frequently used. ATO is a production environment where a product or service can be assembled after receipt of a customer's order. In this environment, many end items can be made from combinations of basic components and subassemblies. The key components (bulk, semi-finished, intermediate, subassembly, fabricated, purchased, packaging, etc.) used in the assembly or finishing process are planned and stocked in anticipation of customer orders. Receipt of an order initiates assembly of the customized product. This strategy is useful where a large number of end products (based on the selection of options and accessories) can be assembled from common components. A very common use of this strategy is in the personal computer industry [6]. The ATO strategy has also been referred to as FTO (Finish To Order). These strategies are implementation of the late customization concept that focuses on stocking a partially built product before the stage where custom features are added [6]. Delivery lead-time is reduced in comparison with MTO because there is little design time required and inventory is held as raw material or parts. Figure 4 shows the operation of the ATO strategy.

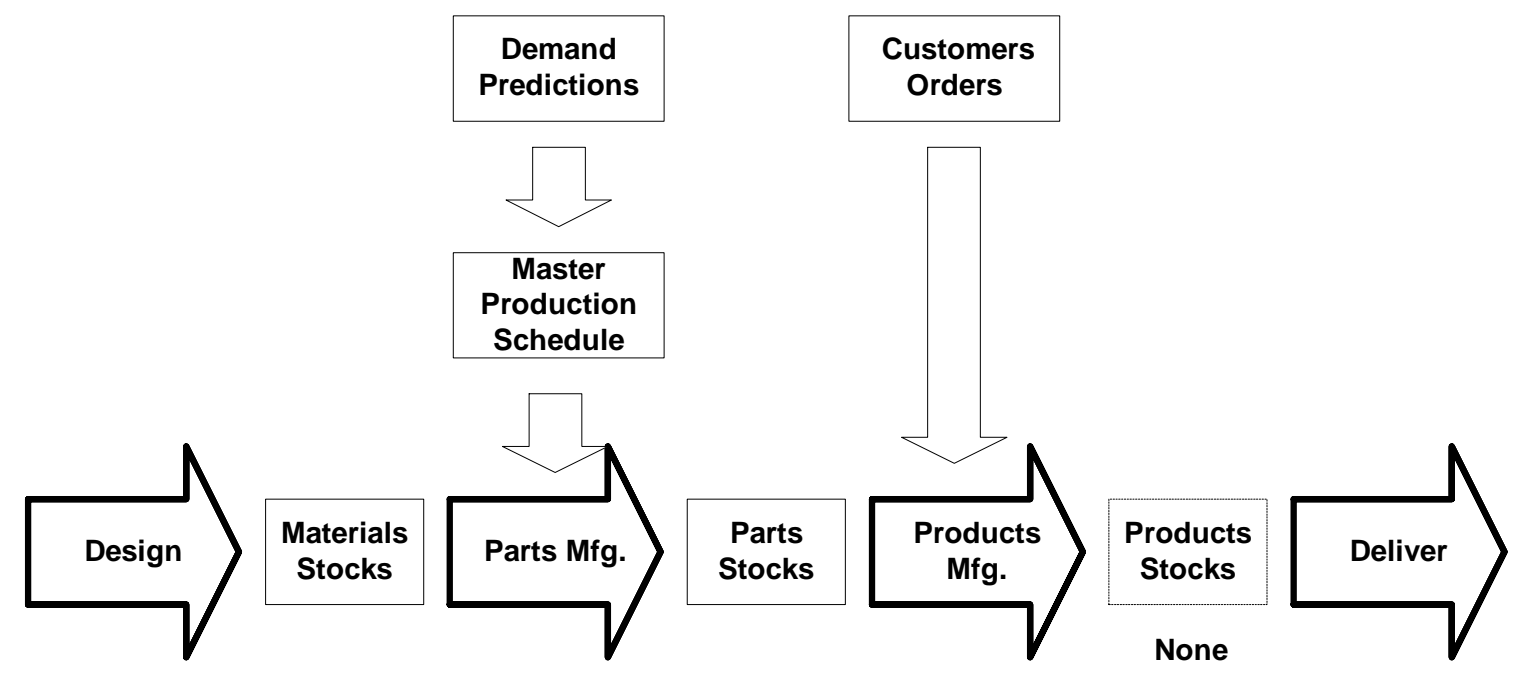

Figure 4. Assemble To Order (ATO) strategy 


\section{Supply chain planning problems}

This section presents common supply chain planning problems. The problems described here are faced by many system designers and managers during design, planning and operation of a supply chain system. The problems are interlinked, as will be clear in the discussion.

\subsection{Primary problems}

\section{(1) Capacity planning problems}

Capacity planning is a process that determines the amount of capacity required to produce in the future. This function includes establishing, measuring, and adjusting limits or levels of capacity. In general, this planning includes the process of determining in detail the amount of labor and machine resources required to accomplish the tasks of production.

In traditional MRP systems (a planning support system for a single factory), there are two methods to estimate and plan the system capacity. One is called Rough-cut capacity planning (RCCP), and the other is so-called Capacity Requirement Planning (CRP), which is a name of a sub-module included in typical MRP systems.

The RCCP is the process of converting the master production schedule into requirements for key resources, often including labor, machinery, warehouse space, suppliers' capabilities, and, in some cases, money. The master-schedule items and quantities are multiplied by the total time required to build each item to provide the total number of hours to produce the schedule. Historical work-center percentages are then applied to the total number of hours to provide an estimate of the hours per work center to support the master schedule. Comparison to available or demonstrated capacity is usually done for each key resource. This comparison assists the master scheduler in establishing a feasible master production schedule.

Similar to RCCP, the CRP module estimates workload on each work center in factories but at a more detailed level. In this case, open shop orders and planned orders in the MRP system are input to CRP. It uses parts routings and time standards to translate into hours at work centers by time period. Even though the RCCP may indicate that sufficient capacity exists to execute the MPS, CRP may show that capacity is insufficient during specific time periods.

These methodologies are also applicable to supply chain systems. These are, so to speak, Rough-cut Supply chain Capacity Planning (RSCP) and Supply chain Capacity Requirement Planning (SCRP). The problem examples for the former are:

- How much capacity individual suppliers should provide to meet the long-range demand mean? These are, for example, number and types of supplier plants, the location of the suppliers, manufacturing capacity of suppliers, the location and capacity of warehouses for transportations, type of manufacturing plants and warehouses, and so on.

- What workload each supplier should handle?

- How much of the raw materials and products should be prepared to ship among suppliers, plants, warehouses, and customers?

The examples for the latter are:

- Which suppliers would be the bottlenecks, when a particular shipment plan is given?

- When and how much production capacity does each supplier need, when the market demand reaches its peak point during a certain time period?

- How much of demand should be supplied from inventory and from production in a certain time period, when a particular demand variation is given?

\section{(2) Resource planning}

Resource planning is capacity planning conducted at the business plan level. It is the process of establishing, measuring, and adjusting limits or levels of long-range capacity. Resource planning is normally based on long-term production plans but may be driven by higher level plans beyond the time horizon for the production plan, e.g., the business plan. It addresses those resources that take long periods of 
time to acquire. Resource planning decisions always require top management approval.

\section{(3) Lead-time planning problems}

The term "Lead-time" has basically two meanings: a span of time required to perform a process (or series of operations), and the time between recognition of the need for an order and the receipt of goods. The second one is often used in a logistics context. Individual components of lead-time can include order preparation time, queuing time, processing time, move or transportation time, and receiving and inspection time. We use this term in this paper with its second meaning. This problem directly impacts the inventory planning problems through the Lead-time inventory, the inventory that is carried to cover demand during the lead-time.

The examples of this class of problems are:

- When and what suppliers should produce, and associated due dates?

- When and how much volume of products or component parts should be transported?

- Which transportation channels should be used?

- Suppose that all of the factories in the chain use a common database for purchase ordering process, what impacts occur on total lead-time in the chain?

\section{(4) Production planning problems}

There are two phases of production planning: the first phase is an aggregate production planning and the second phase is an operational production planning.

An "Aggregate production plan" implies budgeted levels of finished products, inventory, production backlogs, and plans and changes in the work force to support the production strategy. Aggregate planning usually includes total sales, total production, targeted inventory, and targeted customer backlog on families of products.

One of the primary purposes of the aggregate production plan is to estimate the production rates, when the system works according to the given plan. The production rate is an important decision parameter since it determines whether the system is meeting its' management's objective of satisfying customer demand while keeping the work force relatively stable. As the production plan affects many company functions, so it is normally prepared with information from marketing, and coordinated with the functions of manufacturing, engineering, finance, materials, etc.

It is the function of setting the overall level of manufacturing output (production plan) and other activities to best satisfy the current planned levels of sales (sales plan or forecasts), while meeting general business objectives as expressed in the overall business plan such as profitability, productivity, competitive customer lead times, and so on. The sales and production capabilities are compared, and a business strategy that includes a production plan, budgets, pro forma financial statements, and supporting plans for materials and work force requirements, is developed.

Operational production plan is a more detailed set of planned production targets that meet the goal of the higher level manufacturing output plan. It is based on an agreed-upon plan that comes from the aggregate (production) planning function. It is usually stated as a monthly rate for each product family. Measurement units depend on the plan and the products, such as units, tonnage, standard hours, and number of workers. The production plan is management's authorization for the master scheduler to convert it into a more detailed plan, that is, the master production schedule.

\subsection{Secondary problems}

\section{(1) Supplier selection problems}

One of the major issues, when a system planner designs a supply chain or a manager reviews performance of the existing supply chain is the supplier selection problem. It is a significant decision since it affects the system performance for a long time. From the supply chain performance viewpoint it affects all the primary problems discussed above. Examples are as follows:

- Which material is the best to choose for various products? 
- Which supplier is the best to produce and distribute?

- What inventories should be managed by the supplier?

- Where and how much inventories should be stored?

- What is the amount of inventory to be held at the plant and what response time should be expected from the supplier?

\section{(2) Outsource planning problems}

Outsource planning is one of the very important problems for modern manufacturing enterprises. This is because maintaining expertise in all the technologies and processes required for manufacturing a product is almost impossible in single company. In addition to that, a proper outsourcing of process lets a company concentrate its resources on particular core processes, allowing the company to maintain its competitive position. Again, the outsourcing decisions impact all the primary problems discussed above and thus impact the supply chain performance. Examples follow:

- How to determine the set of suppliers for outsourcing and how to select a supplier from the set

- How to choose between third party logistics or self-transportation

- How to link the two processes of internal and external production planning

\section{(3) Operational strategy selection problems}

This problem includes selecting the strategy to operate the supply chain. Suppose that the supply chain designer has solved the primary problems, has selected the best business partners as his/her suppliers and has decided the non-core processes to be outsourced, s/he still needs to decide how to control the flow of products through the supply chain. The problem examples are as follows:

- How to choose between PUSH, PULL, and Hybrid PUSH-PULL

- How to choose the strategy such as STS, MTS, ATO, MTO, at each stage of the supply chain

\section{Simulation as a system performance analysis tool \\ 4.1 Performance measurement}

Designing enterprise systems often needs analysis tools that can estimate its system performance at the design stage itself. This is because of the realization of the enterprise system requires a large investment, regardless of the type of industry. Continuous investment over a long term is often needed to implement a large-scale system. The supply chain system is one of the typical examples of a large-scale system that requires a huge amount of investment to set up.

An analysis tool for supply chain systems should, at least, provide the following general system performance measurements.

- Resource utilization rates: Resource utilization rate is a load factor of system resource. This measurement is used to judge whether the system has enough resources to execute given tasks or not. A resource with high utilization rate indicates that the workload on the resource is comparatively high. If a particular resource shows higher load than other system resources, it would be a bottleneck causing inventories to build up before it. Thus this measure helps identify bottleneck processes in a system. When a system includes a particular bottleneck process, the system performance in general cannot be higher than the bottleneck process performance. A supply chain system is a process chain and individual stages in the process contain many resources each. The performance improvement of bottleneck processes in a chain leads to performance-improvement of the whole system. In this sense, bottleneck identification is the first step of performance improvement of supply chain systems.

- Waiting queue length: Manufacturing and logistics systems can be recognized as process network systems providing services to entities. The process is probably a manufacturing cell, a transporter delivering products to customers, or a computer system recording order forms from customers. These objects often generate queues, when a particular server resource is busy. An entity arriving at a busy server waits until the server is available. Waiting queue length often represents inventory stocks waiting 
for services in manufacturing and logistics systems. When average length of this queue shows high value, it indicates that the server is busy for a high percentage of the time period. This measurement also helps in identification of bottleneck processes in a system. Waiting queue length can be recognized as inventory volumes (including Work-In-Process inventories) in manufacturing and logistics systems. Inventory often works as a shock absorber for unexpected events in these systems, such as machine breakdown. Inventory is also used as a buffer in connection of systems that have different process cycle times. It is indispensable in managing all types of manufacturing systems. However, holding too much inventory brings pressure on manufacturing cost. This measurement is valuable to manufacturing systems for cost-balanced management.

- Throughput rate: This is the number of entities that finish service during unit time at an individual process or the system. This is often called the service rate of the system. This value represents process performance of the server under observation. This measure is frequently used to represent productivity of manufacturing and logistics systems. DGR (Daily-Going-Rate) in a factory is sometimes used to refer to this performance measure. Throughput rate often becomes a target for managing manufacturing and logistics systems.

- Elapsed time: This is amount of waiting time that entities wait until the server is available and the service time that entities receive services from servers. This measurement is often called lead-time in manufacturing systems. For an example, manufacturing lead-time for Make-To-Order (MTO) products is a length of time between the release of an order to production process and shipment to the final customer. In the case of Make-To-Stock products, it is the length of time between the release of an order to the production process and receipt into finished inventory. Purchasing lead-time is often an important measure in supply chain systems. In this context, lead-time means the total lead-time required to obtain a purchased item. Included here are order preparation and release time, supplier lead-time, transportation time, receiving and inspection time, and put-away time.

\subsection{Methodologies comparison}

There are a lot of tools (methodologies) for system performance evaluation. Queuing Network Analysis (QNA) and Petri-Net Analysis (PNA) are typical examples [8][9]. The strength of QNA is that its analysis methodology is based on mathematical formulation as has been shown in MVA (Mean Value Analysis) [10] method. This means that the accuracy of analyzed result is mathematically guaranteed. However, it is applicable only to steady state analysis, and it is based on an assumption that probability distribution functions of service time or arrival rate obey specific forms (e.g., exponential distribution).

On the other hand, the advantage of PNA is that it provides detailed analysis for dynamic behavior of the system. However, it is not suitable for steady state analysis. Timed Petri-Net model, extensions of PN, is applicable to both steady state analysis and transitional analysis. The problem of usage of PNA is that it's modeling of manufacturing and logistics system needs quite high-level of skills to implement practical models. This is because modeling elements are too abstract to represent manufacturing and logistics systems.

Discrete event simulation is the most generic tool for system performance evaluation. Its advantages include:

- It is applicable to both steady state analysis and transitional state analysis.

- The simulation models are, in many cases, represented by elements that are very similar to notations used for representing queuing network.

- It can provide detail models to represent system behaviors, if it is needed.

- The model can represent material-flow, information-flow, and combined material and information flow, if needed.

These advantages enable modeling business process behavior in supply chain systems.

Supply chain system is a queuing network system composed of material source, manufacturer, distributor, retailer, and transporters as the servers at successive stages and the products as entities that traverse the network from raw material stage to the consumers. This structure as a queuing network lends 
itself well for analysis using discrete event simulation. Of course, similar to PN and QN, simulation of supply chains also requires highly skilled analysts.

\section{Requirements and design issues for a generic supply chain simulator}

Implementation of a simulation model requires a modeling view of the target system. This is also true in the case of the supply chain system. This effort proposes modeling a supply chain system from different views relevant for its performance evaluation using simulation.

\subsection{Modeling views of supply chain system}

This section introduces four modeling views for supply chain systems. These are "Organization," "Control," "Activity," and "Communication" as shown in Figure 5. These viewpoints and their interactions help determine the requirement for supply chain simulation.

\section{(1) Organization view}

A supply chain system is composed of member companies organized in a chain or a network. Some of these members belong to the same company, and some of them are independent companies. These members are classified into several categories according to their organizational functions. Although there are many supply chain system participants, they can be classified into six types of organizations. Supply chain members would be classified into the following abstracted types.

- Supplier: "Supplier" owns manufacturing systems to produce products or parts. This organization gets materials from its up-stream chain members, transforms them into value-added objects, and outputs the value-added objects.

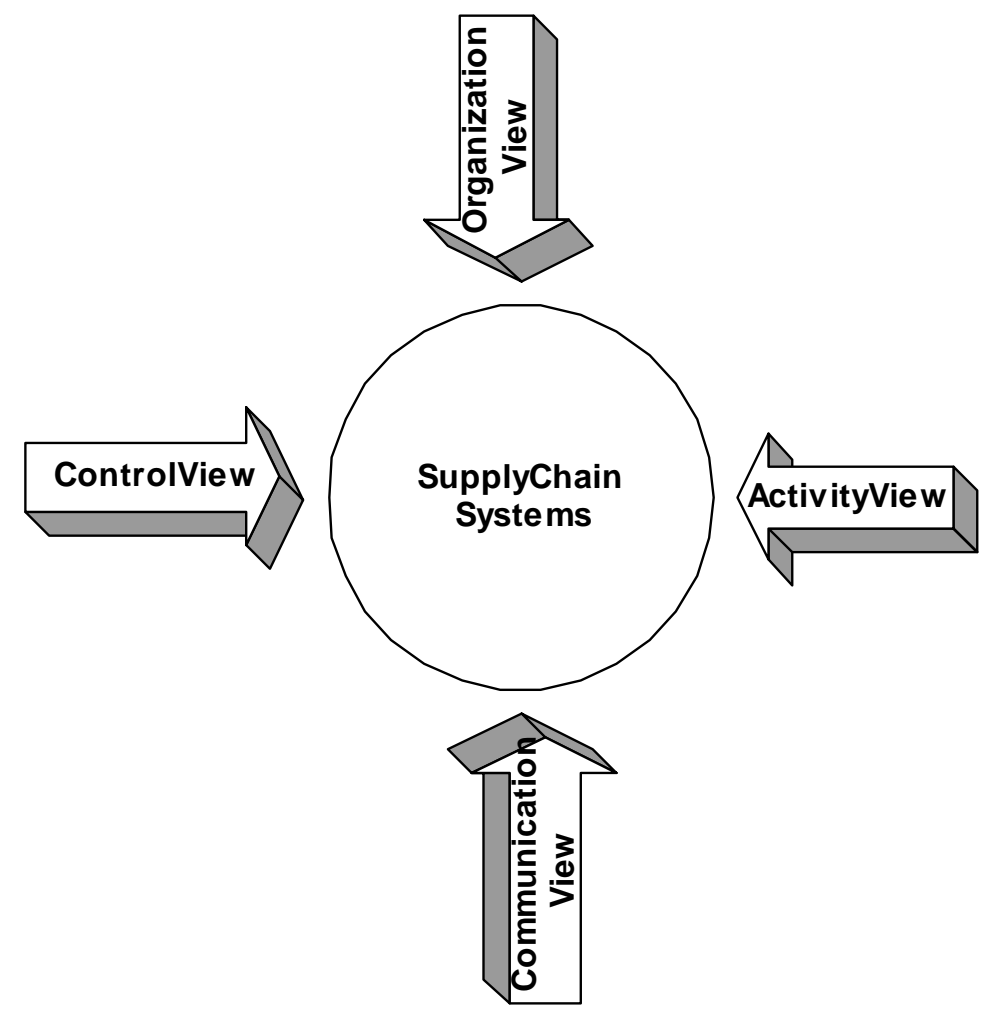

Figure 5. Modeling views of supply chain simulation

- Source: "Source" is a specific supplier that generates materials. This organization is a starting stage of 
material flows in a chain. In many cases, this type of member procures raw materials from outside organizations; however, its operation is abbreviated in the model.

- Storage: "Storage" is a supplier that stores materials until another chain member requires them. A warehouse in a distribution system network is a typical example.

- Deliverer: "Deliverer" transports materials and products from a particular chain member to another. A $3{ }^{\text {rd }}$ Party Logistics (3PLs) company is one of typical examples of them.

- Consumer: "Consumer" purchases products. It generates orders to be provided, and give the orders to planner. This organization is the end stage for material flows.

- Planner: "Planner" makes operational plans across all the members in a chain to deliver products to consumers just in time. The objective of these planning and control is synchronizing their sourcing, manufacturing, and delivering activities with each other. This often plays a role of a supervisor of suppliers. Original Equipment Manufacturers (OEMs), large companies typically producing the product for the end customer, may play the planner role. For example, a large personal computer manufacturer can drive the supply chain and expect its supplier to meet its plans. The central staff for a large company that is vertically integrated and owns multiple stages in a supply chain may also play the planner role.

One supply chain member company may participate in multiple roles. For example, a logistics provider may provide the storage and deliverer roles, each at multiple points in the supply chain. Similarly a member company may own multiple "supplier" roles.

\section{(2) Control view}

The material flow in the supply chain can be viewed using control policies within each organization. Section 2 described material management strategies in manufacturing operations. These operational policies can be applied at a supply chain level and within the operations of each particular chain member. We define here two broad operational policies that control operations of members in a supply chain system: "Schedule driven control" and "Stock-driven control" used primarily with push and pull approaches respectively.

- Schedule-driven control: This control method is based on a central "Master Production Schedule" (MPS). In this system, a planner plays a very important role in a chain. This planner regularly collects demand data by using communication network with market, and it periodically updates the MPS by using accumulated demand forecasting data. The main function of the planner is to give operational orders periodically to supply chain members. The schedule-driven supplier regularly works with the planner as defined in the following operational sequence.

(1) Planner receives purchase orders from consumers.

(2) Planner analyzes accumulated demand data, and develops demand forecasts.

(3) Planner generates MPS (Master Production Schedule), and provides manufacturing orders to each supplier by using MPS.

(4) Supplier works according to the received order. When it finishes a work, it sends finishing signal to the Planner.

- Stock-driven control: This method is based on suppliers' stock volume information. Different from Schedule-driven control, the supplier gives an order to itself by using material stock information at its downstream supplier. The "Stock-driven" supplier always observes a particular stock volume, and it autonomously starts working when the stock volume falls below the predefined replenishment point. This type of supplier generally works according to the following operational sequences.

(1) Supplier periodically observes volume of particular stock that it supplies.

(2) Supplier starts to work, when that stock volume goes below the pre-defined replenishment point.

(3) Supplier has a commitment with Planner on the replenishment point. The Planner occasionally changes this volume based on demand trends information in comparatively long terms.

\section{(3) Activity view}


The third modeling view is "Activity". This view looks at the supply chain as composed of activities at each member organization. Supply chain operations include many activities, however only core activities need to be included in supply chain simulation model. The core activities are classified into the following seven groups.

- Resources and facilities management activities: These are activities for resource and equipment maintenance. (Supplier, Source, Storage, Deliverer).

- Planning activities: These include planning activities for manufacturing, procurement, purchasing, and shipping. The operations are usually planned in accordance with demand data such as customers' order records. (Planner, Consumer)

- Manufacturing activities: These include activities for machining, assembling, disassembling in each supplier, and recording of these activities. (Supplier)

- Transportation activities: These include activities for packaging, shipping, carrying, receiving of materials to be transported. (Deliverer)

- Storing operations activities: These include all of the warehousing activities, such as packaging, storing, picking of materials to be stored. (Storage)

- Material management activities: These include input, output, inspections, and waiting in a queue. They also include activities for inventory management of parts/products, raw materials and so on (Source, Supplier, Deliverer, Storage)

- Communication activities: storing, sharing, sending and receiving data that is exchanged among all of these organizations. (All)

\section{(4) Communication view}

The final modeling view is "Communication." Each supply chain member is activated by communication with another chain member. The communication would be a driving force for sharing information and exchanging data among member companies. The collaboration among chain members is activated through such information sharing and data exchanges. The most important item is to share not only raw market demand data but also processed data that are useful to manage the supply chain system. Supply chain systems usually own a special member (Planner), which plays a central role in communication among chain members. The planner produces processed data and information, which are needed to manage all over the chain. These major data items are used for planning and control in both production and inventory management activities. The communication data can be classified as below.

- Demand forecast data: The planner aggregates demand in each marketing channel in the chain. These are demand trends of finished goods in both the long and medium-term periods. In this process, miscellaneous data communications are derived. This data is used to generate MPS (Master Production Schedule).

- Production planning data: The planner generates the MPS including the production plans at individual suppliers. The processes of this phase are broken down into two types: one is planning and scheduling of operations such as assembly, ordering of component parts; and the other is generated based on the finished goods inventory level.

- Production control data: Suppliers control manufacturing operations and transportation operations by using detail schedules that are broken down from production planning data. This control data is given back to the planner as the activity-logs.

- Inventory planning data: Planner and suppliers make plans of locations and volumes of inventories to be stored. This inventory includes raw materials, intermediate products, and finished goods.

- Inventory control data: Suppliers control inventories to be kept on the predefined level by way of inventory planning. This control data is given back to the planner as the activity-logs.

These data should ideally be maintained at a central server and accessible by all the members of the supply chain. The data may be mirrored in systems at each individual member company. Also, individual member companies in general may share only the data on incoming material and planned shipments of 
products and not the detailed scheduling plans within their facility. One company may be a member of multiple supply chains and this would restrict the data they can share with other members of the supply chains in which they participate. Sometimes, unavailability of end customer demand data may force the upstream members of the supply chain to develop their own forecasts to supplement the order information from downstream members. The robust information system would be needed.

\subsection{A modeling framework for supply chain system simulation}

A supply chain system has four types of modeling views. This section describes a modeling framework for supply chain simulation based on these views. The members in supply chain systems are categorized into six types by way of organization view: These are "supplier," "source," "storage," "deliverer," "consumer," and "planner." Individuals of these are further classified into two types by way of control view: These are "stock-driven" and "schedule-driven." Stock-driven member autonomously work to replenish its relevant inventory stock. Its inventory stock level is often defined as its replenishment point. The schedule-driven member basically works to operational orders given by the planner. Based on this principle, we can define modeling base frame as shown in Table 1.

Table 1. Modeling base-frame

\begin{tabular}{|l|l|l|}
\hline $\begin{array}{c}\text { Organization } \\
\text { view }\end{array}$ & \multicolumn{1}{|c|}{$\begin{array}{c}\text { Control } \\
\text { view }\end{array}$} & Relevant activity view \\
\hline Supplier & Stock- driven & $\begin{array}{l}\text { Supplier observes material stocks of an item in a particular } \\
\text { supplier. The observation target is usually a stock of input } \\
\text { materials at an immediate downstream supplier. When the stock } \\
\text { volume is below the replenishment point, supplier } \\
\text { autonomously starts to work to replenish the target part / } \\
\text { product inventories. }\end{array}$ \\
\cline { 2 - 4 } & $\begin{array}{l}\text { Schedule } \\
\text {-driven }\end{array}$ & $\begin{array}{l}\text { Supplier receives production orders from Planner, which } \\
\text { generates a Master Production Schedule (MPS). It executes the } \\
\text { order, when it receives production orders from the Planner. }\end{array}$ \\
\hline Source & Stock- driven & $\begin{array}{l}\text { Source observes material stocks of an item in a particular } \\
\text { supplier. The observation target is usually a stock of input } \\
\text { materials at an immediate downstream supplier. When the stock } \\
\text { volume is below the replenishment point, source autonomously } \\
\text { starts to work to replenish the target part / product inventories. }\end{array}$ \\
\cline { 2 - 4 } & $\begin{array}{l}\text { Schedule- } \\
\text { driven }\end{array}$ & $\begin{array}{l}\text { Source receives material orders from the Planner, which } \\
\text { generates a Master Production Schedule (MPS). It executes the } \\
\text { procurement orders per the schedule received from the Planner. }\end{array}$ \\
\hline Storage & $\begin{array}{l}\text { Stock- driven } \\
\text { Schedule- } \\
\text { driven }\end{array}$ & $\begin{array}{l}\text { Storage receives materials from other chain members to hold } \\
\text { them, and it autonomously ships materials to replenish stock } \\
\text { inventories at particular suppliers. }\end{array}$ \\
\cline { 2 - 4 } & $\begin{array}{l}\text { Storage receives materials from other chain members to hold } \\
\text { them, and it ships materials when it receives delivery orders } \\
\text { from a planner. }\end{array}$ \\
\hline Planner & $\begin{array}{l}\text { Planner receives orders from Consumers, and sends delivery } \\
\text { orders to deliverer. Planner stores the order as a demand-log. It } \\
\text { predicts products demand in next phase and generates Master } \\
\text { Production Schedule (MPS). This MPS is updated by orders } \\
\text { that are given by the Consumer. The functions of this } \\
\text { organization include: master scheduling, receiving orders from } \\
\text { Consumer, forecasting demands, making commitments on }\end{array}$ \\
\hline
\end{tabular}




\begin{tabular}{|l|l|l|}
\hline & $\begin{array}{l}\text { replenishment with stock-driven members and sending orders } \\
\text { to chain members. } \\
\text { For stock driven stages in the supply chain, the role of the } \\
\text { planner is to set the replenishment points and change them as } \\
\text { required over time due to changes in market and demand. }\end{array}$ \\
\hline Deliverer & $\begin{array}{l}\text { It receives delivery order from other chain members, and it } \\
\text { works according to the delivery order. The sender of this order } \\
\text { is the upstream supplier of this deliverer. }\end{array}$ \\
\hline Consumer & $\begin{array}{l}\text { It gives products purchase orders to a planner. Also inspects } \\
\text { the incoming products for quality and tracking. }\end{array}$ \\
\hline
\end{tabular}

\subsection{Supply chain configuration examples}

Combinations of the modeling base-frames in Table 1 can be used to define the configuration of supply chain systems. This section demonstrates typical configurations of supply chain systems by using the above modeling base-frames. One is a schedule-driven supply chain system, and the other is a stock-driven supply chain system.

Figure 6 represents a configuration example of a schedule-driven supply chain system. In this system, a planner of the chain receives purchase orders from consumers and it gives production orders to each chain member. Every supplier produces products according to orders given by the supply chain planner. A particular member might receive orders directly from other chain members as is shown in the deliverer in this case.

Connection of schedule-driven members results in a supply chain operating as a push system. The planner plays a very important role in this system. The planner gets purchase orders from consumers and accumulates past order data to predict demands in the future. It further generates production orders and communicates them to individual chain members. The planner needs to collect various kinds of data from the chain members so as to give proper orders to each member. This configuration results in concentration of data and information with the planner, and the success of the supply chain is dependent on the decision-making capability of the planner.

A particular supplier might operate using stock-driven control. When the system includes such members, commitment would be needed between the supplier and the planner. An example illustrated in Figure 7 includes a stock-driven source that autonomously provides materials to the parts supplier.

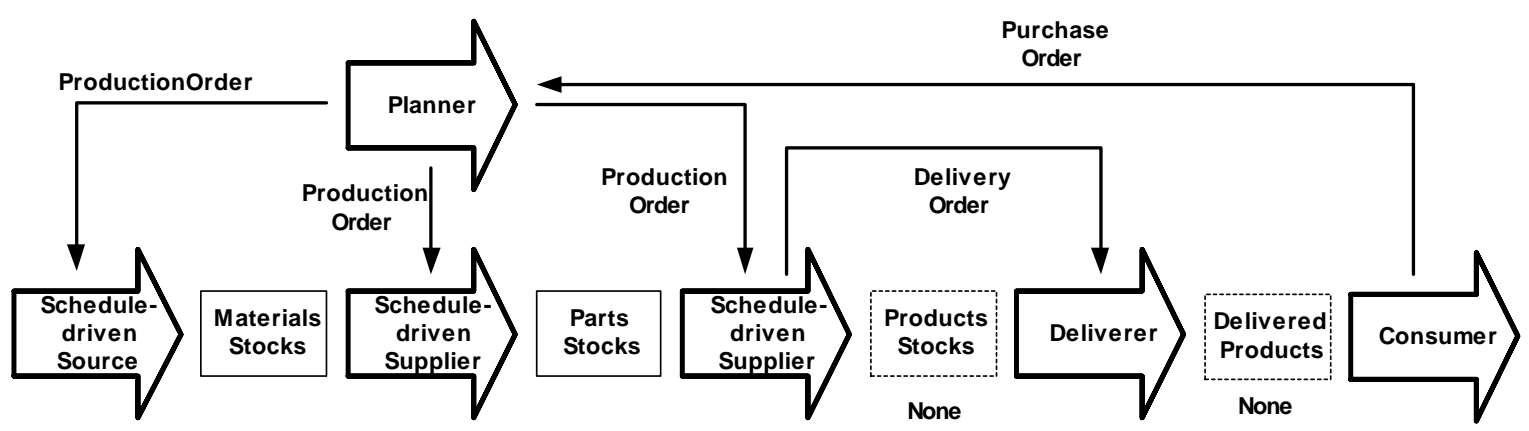

Figure 6. A configuration example of schedule-driven supply chain 


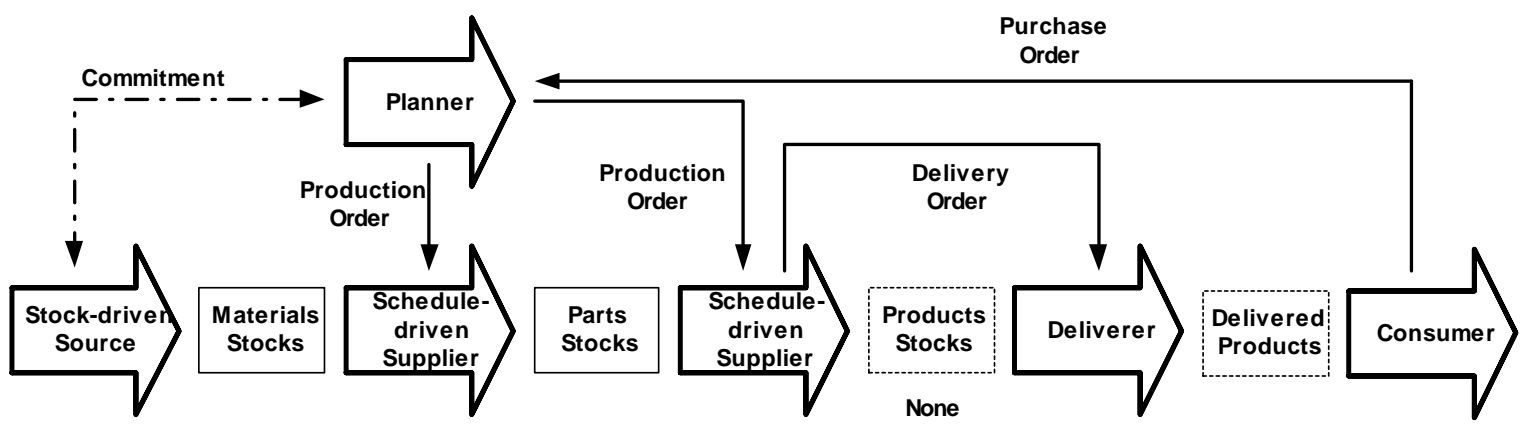

Figure 7. A configuration example of hybrid schedule and stock driven supply chain

Figure 8 illustrates a configuration example of a purely stock-driven supply chain system. In this system, a planner receives a commitment from the suppliers to provide materials and parts. Every supplier works autonomously to provide materials to individual downstream suppliers. The data and information are distributed to the individual supplier, and the planner's direct control on suppliers is minimized in this system.

Connection of the stock-driven members makes a pull system. The role of the planner is less important here than in the case of a push system. The individual stock-driven supplier autonomously works according to the predefined operational commitments with the planner. The planner plays a role of communicator between consumers and the final product plant. Another role of the planner is to define the replenishment points and receive operational commitments from suppliers for maintaining the stock. The role of planner is more of a data communication enabler rather than a controller of suppliers.

A particular supplier might operate in a schedule-driven style within a stock-driven supply chain. An example illustrated in figure 9 shows a schedule-driven supplier that is controlled by a planner (A final product plant in this case). The planner receives purchase orders from consumers and gives production orders to a final product plant in the chain. Other suppliers in the chain operate in stock-driven mode. They autonomously provide materials to the individual downstream supplier. This configuration can reduce product stock cost, which is a major contributor to the inventory costs.

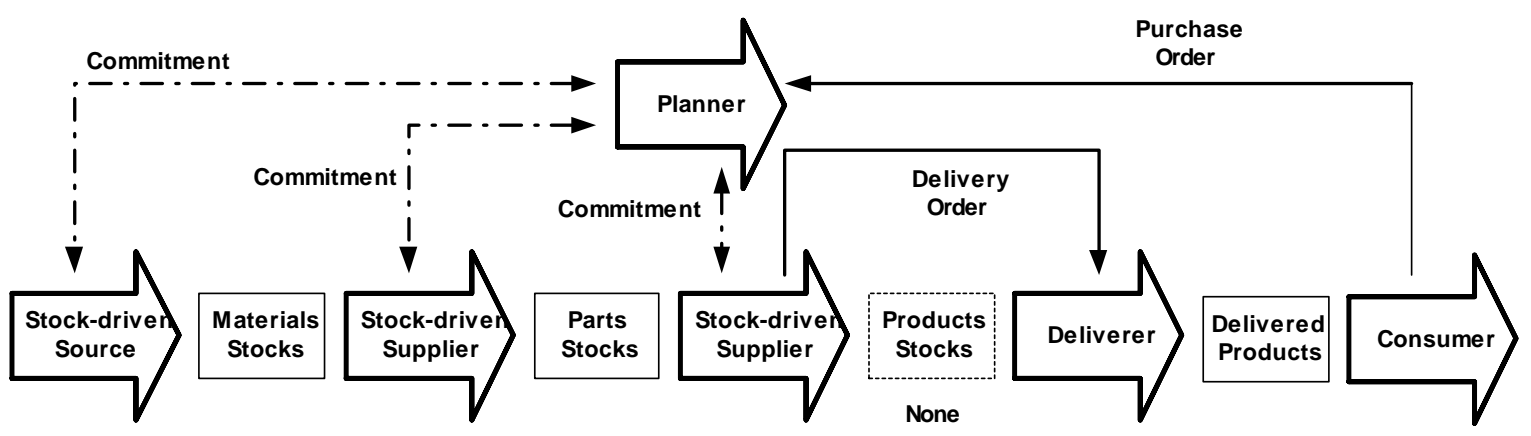

Figure 8. A configuration example of stock-driven supply chain 


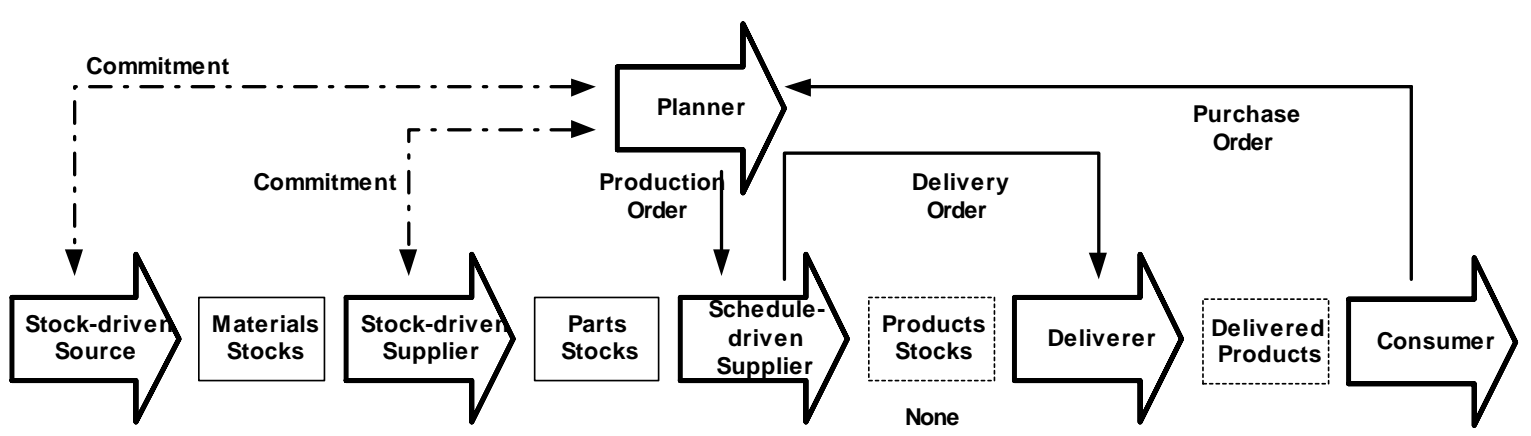

Figure 9. A configuration example of hybrid-type stock-driven supply chain

\section{Major data items for the simulator}

\subsection{Control-view-specific descriptions}

Stock-driven operation represents an organization's operations that autonomously execute by way of a pre-defined inventory stock level downstream. The organization periodically observes volumes of the parts and materials at a predefined stock point, typically at the immediate downstream supplier. When the volume falls below the predefined replenishment level, it starts to generate and ship materials. This generation and shipment stops when the volume of materials at specified suppliers reaches a predefined stock volume level. Description of such operation requires the following data items.

- "Material group" that is relative to this operation.

- Data on inventory stock, such as "material name," "id," and its owner "supplier's name."

- "Replenishment volume level" that is the minimum criteria volume of inventory. When the volume would fall below this level, this operation starts autonomously.

- "Stock volume level" is the maximum volume of inventory. When the volume would reach this level, the operation stops autonomously.

- "Committed lead time" by which the supplier has to provide the replenishment stock.

- "Shipment batch quantity" defines the quantity in which the replenishment batches are shipped.

Schedule-driven operation generally represents an organization's operations that execute by way of orders based on MPS by the supply chain planner. When it receives orders, it starts the predefined operation to produce the ordered quantity. Description of such an operation requires the following data items.

- "Material group" that is relative to this operation

- "Sender" (planner) of this order

- "Order Data" including:

o "Material name," "id," "total quantity" and "shipment batch quantity"

o "Order-date" that this order is placed

o "Due-date" that this order should be completed

\subsection{Organization-view-specific descriptions}

\subsubsection{Source}

The source generates materials to provide to other chain members. The data description for Stock-driven sourcing operation is the same as for stock-driven operation defined in control-view-specific description. The committed lead-time in this case is also referred to as the "Sourcing lead-time." 
The data description for the Schedule-driven sourcing operation is the same as for schedule-driven operation defined in control-view-specific description. The "order" and "lead-time" may be referred to as "Sourcing order" and "Sourcing lead-time" respectively for this organization.

\subsubsection{Supplier}

The supplier transforms incoming material into its next state and supplies it to the next downstream supplier or customer. The data description for Stock-driven supplier operation is the same as for stock-driven operation defined in control-view-specific description.

The data description for Schedule-driven supplier operation is the same as for schedule-driven operation defined in control-view-specific description. The "order" may be referred to as "Manufacturing order" for this organization.

\subsubsection{Storage}

The storage receives part / products from other organizations and holds them until needed by the downstream supplier or customer. For Stock-driven storage operation the shipments are sent when the material volume at specified suppliers falls below the predefined replenishment point. The data description for Stock-driven storage operation is the same as for stock-driven operation defined in control-view-specific description.

The data description for Schedule-driven storage operation is the same as for schedule-driven operation defined in control-view-specific description. The "order" may be referred to as "Shipment order" for this organization.

\subsubsection{Deliverer}

Delivery operation represents operations of the organization "Deliverer." This works according to the delivery orders given by other organizations, usually the up-stream organizations in the material flow of the chain. Description of this operation requires the following data items.

- "Material group" that is delivered by this organization.

- List of "Delivery lead-time," "upstream supplier," and "downstream supplier or customer."

- "Shipment Order Data" including:

(1) "Material name," "id" and "shipment batch quantity."

(2) "Order-date" that this order is given.

(3) "Due-date" that this order should be delivered.

\subsubsection{Planner}

Planning operation represents operations of the organization "Planner." Major tasks of this organization are forecasting demands and giving orders to chain members. Market demand forecasting in actual business practice is a complex task requiring various types of analyses on both numerical and non-numerical data. These data analyses processes are hard to represent as simulation models. The forecasting processes can be approximated in the simulation model using a simplified numerical method, called the "exponential smoothing method."

It is important to model the concept of "planning phase" to model this organization. In the following description of the planner's tasks, we assume that the current phase is represented as (i)-th phase. This organization repeats the following operations for each pre-defined planning cycle time.

(1) It receives purchase orders from consumers. ((i)-th order)

(2) It gives delivery orders ((i)-th order) to the deliverer that transports products to consumers, if it owns deliverable stock.

(3) It gives production orders ((i)-th order) to the final product suppliers.

(4) It adds the current purchase order ((i)-th order) from consumers into a demand record dataset. 
(This dataset includes all data that is given by consumers until (i)-th phase.)

(5) It predicts purchase demands in next ((i+1)-th) time phase by using the demand record dataset.

(6) It gives production orders $((i+n)$-th predicted order) to the $n$-th tier suppliers by using predicted demand data, if the suppliers belong to schedule-driven types.

(7) It defines replenishment level data and may provide orders, if particular stock-driven suppliers need supplementary orders from the planner.

Demand forecasting techniques are needed in step (5) of the above planning process. The selected exponential smoothing method is one of the most popular methods. An advantage to exponential smoothing is that the new data can be given any desired weight taking into account the soft information available to the planner. The weight given to the latest demand is called a smoothing constant and is represented by alpha $(\alpha)$. This value is always expressed as a decimal from 0 to 1.0 . The formula for calculating the new forecast is:

New forecast $=\alpha$. latest demand $)+(1-\alpha)($ previous forecast $)$

The data record of the stored demand dataset, which is used to forecast demands, should include the following records.

- $\quad$ Order-Id: Identifications of purchase orders from the consumer.

- $\quad$ Consumer name, Consumer Id: Consumer's name and identification.

- $\quad$ Ordered date: The date that the planner receives the order from the consumer.

- $\quad$ Product name, Product id: The name and identifier of the product that the consumer ordered.

- Volume of Product: The volume of the product that the consumer indicated in its purchase order.

- $\quad$ Delivery due-date: The due-date that the consumer required the delivered date of product.

Using the demand dataset, the planner generates the orders for suppliers with data items as defined for the schedule-driven operations or the replenishment levels with data items as defined for stock-driven operations in section 6.1.

\section{Other requirement for supply chain simulation}

\subsection{Input data analysis and output analysis}

Discrete event simulation is classified into two types from the view of input parameters: deterministic simulation and stochastic simulation [11]. In deterministic simulation, all parameters have deterministic values. A typical example of this is the use of simulation for scheduling, that simulates a given supply scheduling rule or philosophy and uses deterministic process times. Typical examples of questions answered by this simulation are:

(1) How much volume of products can be produced by a particular supplier in a day?

(2) How much weight or how many lots of products a transporter can deliver from a supplier to the final product factory in a given time period?

(3) How many lots of products can a supplier store in a particular warehouse?

Deterministic simulation is usually executed using a single run simulation with given parameters.

Stochastic simulation uses parameters that are given probabilistic values by random number generation mechanisms. The examples of these parameters are job processing time, transportation time, part reject rates in acceptance inspections, consumers' demand in next phase, etc. These data are explicitly represented as probability distribution functions with defined parameters in simulation models.

It is often difficult to estimate these probability distribution functions and their parameters. This is because the practitioners do not have enough data collected for meeting the assumptions of a distribution function and its parameters. Standard distributions such as normal and exponential are commonly used in simulation input modeling due to such difficulties. In these cases, simulation practitioners should choose a high-quality random number generation function. 
Discrete event simulation is also classified into two types from the view of simulation output data: steady-state simulation and terminating simulation [12]. The decision on type of simulation depends on the simulation objectives. The application of each simulation type is as follows.

- Steady-State simulation: The purpose of this simulation is the study of long-run behavior of the system of interest. A performance of a system is called a steady-state parameter if it is a characteristic of the equilibrium distribution of an output stochastic process. For example steady state simulation may be used for supply chain systems to determine the average lead-time of the delivered products.

- Terminating simulation: In this case the simulation starts in a specific state, such as the empty and idle state, and is run until a defined terminating event occurs. The output process is not expected to achieve any steady-state behavior and any parameter estimated from output data is a transient value. For example terminating simulation may be used for a supply chain network simulation, to determine the time until $\mathrm{n}$ orders are completed. The terminating replicated simulation will be the most useful for supply chain problems described in section 3 .

Stochastic simulation requires substantial output data analysis. The simulation results generally depend on pseudo random numbers that are generated in a computer. Results from a single simulation run might show a result very different from true estimations, and hence more advanced output analysis involving multiple runs or one long run visualized as multiple runs is required.

There are several methods to analyze simulation outputs, such as "Batch-means method," "Regenerative method," and "Independent replication method." The first two methods are used to analyze steady-state simulations only, while the "Independent replication method" is applicable to both types of simulation. Each method requires removal of initialization bias for steady-state simulations. The output items are evaluated as values with 1- $\alpha$ confidence interval, where $\alpha$ is an error probability. For an example, the mean of the observed data is represented as the following range.

$$
\left[\bar{X}_{k}-t_{k-1,1-\alpha / 2} \frac{S_{k}(X)}{\sqrt{k}}, \bar{X}_{k}+t_{k-1,1-f_{i} / 2} \frac{S_{k}(X)}{\sqrt{k}}\right]
$$

Where $\bar{X}_{k}$ is mean of k observations, $S_{k}(X)$ is the estimated variance, and $t_{k-1,1_{-\alpha / 2}}$ is the observation from t-distribution with the defined parameters in the subscript. Credible system performance analysis using discrete event simulation needs both input data analysis and output data analysis.

\subsection{Simulation experimental design}

Supply chain simulation, whether steady-state or terminating, is generally a large-scale analysis, since it contains a large number of system parameters. Execution of simulation often needs long computation times. Simulation practitioners must consider efficient methods for simulation experiments.

General design theory for methodologies of such experiments is so-called "Design Of Experiments" (DOE) [13]. DOE is a statistical technique and is applicable to any type of simulation experiments.

Full factorial design considers all combinations of simulation parameters. If a simulation has 3 parameters $(\mathrm{X}, \mathrm{Y}, \mathrm{Z})$ and each parameter has 2 values respectively, the total number of runs required to evaluate each combination would be $8\left(=2^{3}\right)$. In a simple supply chain simulation involving three stages, $\mathrm{X}, \mathrm{Y}$, and Z may be the lead time at each stage. The combination of parameters value is shown in Table 2 . The effect of parameter $X$ is, for an example, shown in comparison between summation from case 1 to 4 and summation from case 5 to 8 . This method is applicable only when simulation scale is very small. The number of required simulation runs to evaluate all combinations increases exponentially with the number of parameters. For example, for ten parameters, the number of required simulation runs to evaluate all combinations would be $2^{10}=1024$.

Table 2. Full factorial design of simulation (3 parameters with 2 values) 


\begin{tabular}{|c|c|c|c|}
\hline Parameter & X & Y & Z \\
\hline Case 1 & 1 & 1 & 1 \\
\hline Case 2 & 1 & 1 & 2 \\
\hline Case 3 & 1 & 2 & 1 \\
\hline Case 4 & 1 & 2 & 2 \\
\hline Case 5 & 2 & 1 & 1 \\
\hline Case 6 & 2 & 1 & 2 \\
\hline Case 7 & 2 & 2 & 2 \\
\hline Case 8 & 2 & 2 & 2 \\
\hline
\end{tabular}

Fractional factorial designs are used, when higher-level interactions among factors can be ignored. Prominent classical methods for these designs were introduced by Placket and Burman in 1946. These are two-level fractional factorial designs in $\mathrm{k}$ variables where the number of design points, $\mathrm{N}$, is equal to $\mathrm{k}+1$. These designs are available only when $\mathrm{N}$ is a multiple of 4 .

As for more practical methods, we propose usages of "Orthogonal Array." These are convenient ways to design simulation experiments composed of multiple simulation parameters. The usage of these arrays can significantly reduce the number of required simulation runs for a system involving many parameters. An example of the "Orthogonal Array" is shown in Table 3. This table $\left(\mathrm{L}_{8}\left(2^{7}\right)\right)$ is applicable to an experiment that includes 3 parameters with 2 values and their full interactions among these parameters.

Table 3. Orthogonal Array $\mathbf{L}_{8}\left(2^{7}\right)$

\begin{tabular}{|l|l|l|l|l|l|l|l|}
\hline & 1 & 2 & 3 & 4 & 5 & 6 & 7 \\
\hline 1 & 1 & 1 & 1 & 1 & 1 & 1 & 1 \\
\hline 2 & 1 & 1 & 1 & 2 & 2 & 2 & 2 \\
\hline 3 & 1 & 2 & 2 & 1 & 1 & 2 & 2 \\
\hline 4 & 1 & 2 & 2 & 2 & 2 & 1 & 1 \\
\hline 5 & 2 & 1 & 2 & 1 & 2 & 1 & 2 \\
\hline 6 & 2 & 1 & 2 & 2 & 1 & 2 & 1 \\
\hline 7 & 2 & 2 & 1 & 1 & 2 & 2 & 1 \\
\hline 8 & 2 & 2 & 1 & 2 & 1 & 1 & 2 \\
\hline Component & $\mathrm{a}$ & $\mathrm{b}$ & $\mathrm{c}$ & $\mathrm{c}$ & $\mathrm{a}$ & $\mathrm{b}$ & $\mathrm{a}$ \\
\hline & & & & $\mathrm{b}$ & $\mathrm{c}$ & $\mathrm{c}$ & $\mathrm{b}$ \\
\hline & & & & & & & $\mathrm{c}$ \\
\hline
\end{tabular}

\section{Conclusion}

This paper discussed general manufacturing operations strategies, supply chain planning problems, and current simulation technologies from views of performance evaluation. Based on these discussions, modeling requirements and design issues for a supply chain simulation system were defined. A simulation modeling framework based on the system modeling views was presented.

The key points of this report are summarized as follows.

- Modeling base-frames based on four modeling views, which are "Organization," "Control," "Activity," and "Communication."

- Clarification of typical configurations of supply chain systems: stock-driven, order-driven, and their mixed types.

- Operational descriptions in an individual supplier organization: These descriptions may be directly translated into modeling language that is provided by simulation software, and finally, 
- Discussion of output data analysis and simulation experiments design.

The benefits of the proposed supply chain simulation modeling methods are summarized as follows.

- Modeling flexibilities: The model builders can implement models by using modeling base-frames shown in Table 1.

- Scenario analysis: Manufacturing system analysts can implement several types of simulation models based on the same resources and different operational scenarios. For example, a particular supplier operates in stock-driven mode. If this supplier operates in order-driven supplier mode, what is the impact of this change in the operations policy?

- Analysis of system sensitivities: Utilization of experimental design methods provides efficient simulation experiments. Especially, use of orthogonal arrays lead to significant reduction in the required number of simulation runs.

The proposed modeling base-frames can be further expanded with facilities for modeling costing estimations, such as for manufacturing and transportation activities. A relevant costing measurement method is the activity-based-costing (ABC) method. Future work will evaluate addition of several parameters for this purpose to the proposed modeling base-frames.

\section{References}

[1] Kurt Salmon Associates, Inc., Efficient Consumer Response: Enhancing Consumer Value in Grocery Industry, Food Market Institute, Jan. 1993

[2] D. Weeks, and F.A. Crawfold, Efficient Consumer Response: A Mandate for Food Manufacturers?, Food Processing, Feb. 1994.

[3] The ECR Performance Measures Operating Committee, Performance Measurement, Applying Value Chain Analysis to the Grocery Industry, Joint Industry Project on Efficient Consumer Response, 1994.

[4] Supply Chain Operations Reference Model: Overview of SCOR Version 6.0, Available online at http://www.supply-chain.org/.

[5] XML Common Business Library, Version 3.5. Available online at http://www.xcbl.org/xcbl35/ $\mathrm{xcbl35.html;} \mathrm{OASIS} \mathrm{Universal} \mathrm{Business} \mathrm{Language,} \mathrm{Available} \mathrm{online} \mathrm{at}$ http://www.oasis-open.org/committees/tc_home.php?wg_abbrev=ubl; etc.

[6] Sanjay Jain, N.F. Choong and W. Lee, 2004, "Strategy Evaluation for Mass Customization of Personal Computers," Submitted to International Journal of Computer Integrated Manufacturing.

[7] Arnold, T. \& Chapman, Introduction to Materials Management 4th edition, Prentice Hall, Inc., 2001

[8] Rajan Suri and Gregory W. Diehl: A Variable Buffer-size Model and its Use in Analyzing Closed Queueing Networks with Blocking, Management Science, 32, 2, 1986.

[9] H.Alla and P. Ladet, Colored Petri Nets: A Tool for Modeling, Validation, and Simulation of FMS, in Flexible Manufacturing Systems: Methods and Studies (ed. A.Kusiak), Elsevier, New York, 271-281, 1986.

[10] Martin Reiser and S.S. Larvenbarg, Mean Value Analysis of Closed Multi-chain Queueing Networks, Journal of the ACM, 27, 2, 313-322, 1980.

[11] J. Banks etc (eds.) Handbook of Simulation, 1998.

[12] Jack P.C. Kleijinen: Statistical Tools for Simulation Practitioners, Marcel Dekker Inc.,1987.

[13] G.S. Peace, Taguchi Methods, Addison Wesley, 1993. 